\title{
Is manipulation under anaesthesia still a better option than intra articular steroid injection in primary frozen shoulder?
}

\author{
Raghav Ravi Veeraraghavan, Venatius Varghese*, Sanjay A. K., \\ Pravin Kumar Vanchi, Mohan Kumar Murugesan
}

\begin{abstract}
Department of Orthopaedics, Sri Ramachandra Institute of Higher Education and Research, Chennai, Tamil Nadu,
\end{abstract} India

Received: 12 November 2019

Revised: 31 December 2019

Accepted: 02 January 2020

\section{*Correspondence:}

Dr. Venatius Varghese,

E-mail: venown@gmail.com

Copyright: (c) the author(s), publisher and licensee Medip Academy. This is an open-access article distributed under the terms of the Creative Commons Attribution Non-Commercial License, which permits unrestricted non-commercial use, distribution, and reproduction in any medium, provided the original work is properly cited.

\section{ABSTRACT}

Background: Frozen shoulder, also known as adhesive capsulitis, is a common cause of a painful shoulder with restricted motion. The best treatment of frozen shoulder is prevention (secondary frozen shoulder), but early intervention is paramount; a good understanding of the pathologic process by the patient and the physician also is important. The aim of study is comparison between closed manipulation under anaesthesia and intra articular steroid injection in primary periarthritis shoulder.

Methods: 30 patients each with primary frozen shoulder who were treated either with closed manipulation under anaesthesia and intra articular steroid injection. The patient is reassessed after 2 weeks, 1 month, 3 month and 6 months using shoulder pain and disability index (SPADI) and visual analogue scales (VAS) to compare the groups.

Results: The SPADI index found to be better with patients under went closed manipulation under anaesthesia than intra articular steroid injection in the first 2 weeks. Follow up shows $1^{\text {st }}$ group shows better outcome than $2^{\text {nd }}$ group at 1 month, but later on 3 months and 6 months shows comparable results. VAS score shows initial period of improvement in pain with steroid injection ( $2^{\text {nd }}$ group). Final follow up shows better pain relief with manipulation under anaesthesia group.

Conclusions: The immediate treatment outcome is better with patients with primary frozen shoulder underwent closed manipulation under anaesthesia although following months outcome shows almost equal effectiveness with steroid injection.

Keywords: Frozen shoulder, Closed manipulation under anaesthesia, Physiotherapy, SPADI

\section{INTRODUCTION}

Frozen shoulder (FS) or adhesive capsulitis is one of the most common shoulder pathology of shoulder pain and restricted motion. Neviaser coined the term adhesive capsulitis to describe a contracted, thickened joint capsule that seemed to be drawn tightly around the humeral head with a relative absence of synovial fluid and chronic inflammatory changes within the subsynovial layer of the capsule. ${ }^{1}$ The pathophysiology of idiopathic FS is still poorly understood. ${ }^{2}$ FS is traditionally divided in three stages. ${ }^{3}$ Stage two is the "frozen stage" with established stiffness and reduced pain at rest, but still painful at the end of the range of motion. Conservative treatment, most frequently consisting of physiotherapy and corticosteroid infiltrations, is considered appropriate for the majority of patients. ${ }^{4}$ There are several invasive treatment procedures possible, like manipulation under anaesthesia (MUA), arthroscopic capsular release and hydrodilatation. However, good quality comparative studies concerning these procedures are scarce. MUA is a short and relative simple procedure by which capsular adhesions are torn 
apart by manipulation, with the potential to rapidly restore the range of motion and reduce symptoms within days after the procedure. ${ }^{5}$ Similarly, various studies on intra-articular corticosteroids used in combination with physiotherapy resulted in better outcomes compared to intra-articular corticosteroids alone. ${ }^{6}$ A systematic review of randomized-controlled trials and concluded that intraarticular corticosteroid injections lead to greater improvements in pain relief and range of motion both in the short and the long terms, but compared to other treatments, the effects were similar in the long term. ${ }^{7}$ So we are framing a study to compare manipulation under anaesthesia and intra articular steroid injection.

\section{METHODS}

This was a prospective study done at department of Orthopaedics, Sri Ramachandra Institute of Higher Education and Research, Chennai, India during the period of December 2017 to December 2018. This was done in accordance with code of ethics of the world medical association for experiments involving humans (declaration of Helsinki). Institutional ethics committee approval was obtained. The inclusion criteria are patient age more than 18 years having symptoms more than 1 year. Frozen shoulder was defined as the presence of shoulder pain with limitation of both active and passive range of motion in glenohumeral joint $\leq 25 \%$ in at least 2 directions: flexion, abduction, external and internal rotation, as compared with normal values or contra lateral shoulder. ${ }^{8}$ Patients were excluded if their disorder was secondary to inflammatory, degenerative, metabolic (except for diabetes mellitus), trauma, septic arthritis and cerebrovascular accident. Diabetic patients were matched in treatment groups. Patients, who had been treated with injection or physiotherapy in last 6 months, were also excluded.

We had totally 60 patients who took part in the study. Informed written consent was obtained from all patients. They were separated into 2 groups. Age, sex, duration of disease, level of education, employment, diabetes mellitus, visual analogue scales (VAS) score, shoulder pain and disability index (SPADI) score and active and passive range of motion were recorded at baseline. ${ }^{9-12}$ The first group underwent shoulder manipulation under anaesthesia after obtaining anaesthesia fitness. During the procedure, the patient was supine position and typical rasping noise occurring during manipulation confirmed the clinical diagnosis of frozen shoulders, the affected extremity is lifted and pushed the upper arm in flexion and abduction. After the shoulder was stretched into flexion, the elbow was flexed to a right angle, and the upper arm was gently rotated into internal and external rotation. Normal or nearly normal mobility was achieved during the procedure. Following procedure all patients received continuous passive exercise. After discharge, exercise training with a physiotherapist in our physiotherapy department was continued until the range of motion was satisfactory. SPADI index and VAS score is recorded during the follow up visits on 2 weeks, 1 month, 3 months and 6 months.

The second group patients are given intraarticular triamcinolone $40 \mathrm{mg}$ injection with $2 \%$ lignocaine to involved shoulder under sterile precautions. ${ }^{13,14}$ Followed by passive range of motion exercise were started. Patients are followed up for 2 weeks, 1 month, 3 months and 6 months during which SPADI index and VAS score is recorded.

\section{RESULTS}

For the study we enrolled 60 patients more than 18 years of age, 2 of them refused to be part of the study as they were not able to show up for the follow up. So, we conducted the study in the rest 58 patients (29 patients each in group). The mean age in $1^{\text {st }}$ group was 51.34 and for $2^{\text {nd }}$ group was 52.76 and male to female ratio was 10:19 and for $2^{\text {nd }}$ group was 20:9 respectively. The VAS and SPADI index for both groups were tabulated in Table 1 and 2. We had no cases of adverse effects or side effects following intra articular injection as well as MUA. There is initial improvement with intraarticular steroid injection with physiotherapy in view of VAS score although the final outcome is better with manipulation under anaesthesia with physiotherapy in 6 months follow up study. Mean SPADI score shows initial significant improved with first group (MUA and PT) compared to group 2 (intraarticular steroid injection and PT). The final follow-up shows better improvement with 1st group than 2nd group.

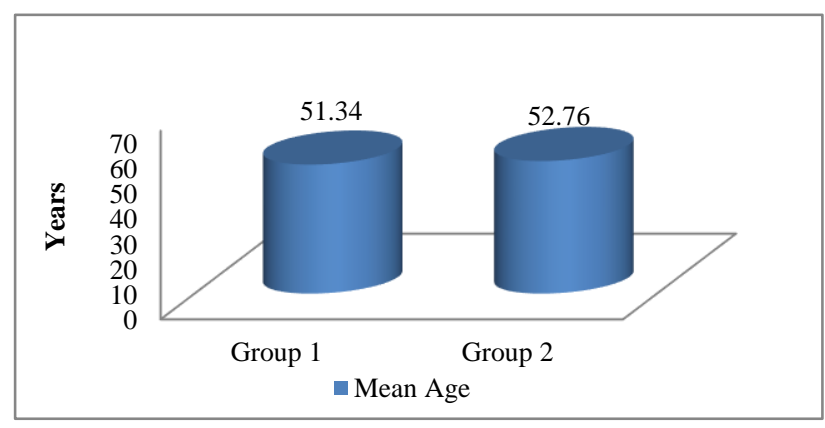

Figure 1: Mean age distribution.

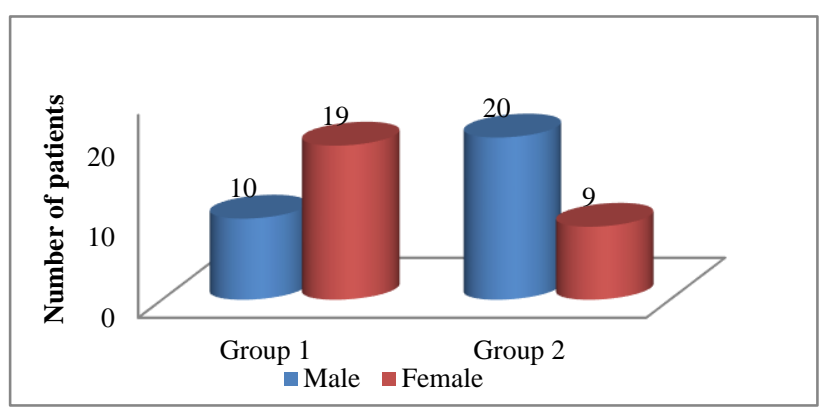

Figure 2: Sex distribution. 
Table 1: Mean VAS score.

\begin{tabular}{|llllll|}
\hline Group & Initial visit & 2 weeks & 1 month & 3 months & $\mathbf{6}$ months \\
\hline MUA and PT & 6.2 & 3.2 & 3.5 & 4.0 & 5.0 \\
\hline PT and IAI & 6.3 & 3.0 & 3.2 & 3.9 & 5.1 \\
\hline
\end{tabular}

MUA: manipulation under anaesthesia; PT: physiotherapy; IAI: intraarticular steroid injection.

Table 2: Mean SPADI index.

\begin{tabular}{|llllll|}
\hline Group & Initial visit & $\mathbf{2}$ weeks & $\mathbf{1}$ month & $\mathbf{3}$ months & $\mathbf{6}$ months \\
\hline MUA and PT & 66 & 46 & 36 & 25 & 10 \\
\hline PT and IAI & 67 & 55 & 40 & 27 & 14 \\
\hline
\end{tabular}

MUA: manipulation under anaesthesia; PT: physiotherapy; IAI: intraarticular steroid injection.

\section{DISCUSSION}

Frozen shoulder is a common, sometimes painful, but ultimately self-limiting, condition that is usually managed in the primary care setting with a combination of analgesics, injections, and physiotherapy. In our study the mean age group in both groups were $6^{\text {th }}$ decade. FS mainly affects individuals 40-60 years of age, with a female predominance. ${ }^{15}$ Some authors consider manipulation as an effective intervention, whereas others claim that it is traumatizing and may even exacerbate pain. ${ }^{16}$ Our study showed that the VAS score decreased intra articular steroid injection on initial 2 weeks to 3 months, although the final follow of 6 months showed better outcome with MUA. Meyer et al report that $90 \%$ of their patients with an idiopathic FS were unable to work, but that $80 \%$ were able to return to work six months after MUA. ${ }^{17}$ SPADI index for patient underwent MUA had lower scores during the initial follow compared to other group which underwent intra articular steroid injection with physiotherapy. The method of MUA in the management of frozen shoulder remains disputed, with the frequently cited criticism being an absence of evidence to suggest it ultimately changes the outcome from the natural course of the disease.

In a study of Kivimäki et al 6 months follow up shows MUA does not show much effectiveness along with shoulder exercise comparing with shoulder exercise along. ${ }^{18}$ In our study MUA shows better results throughout the follow up of 6 months comparing physiotherapy (shoulder exercise) but the latter group was given intra articular steroid injection. In another similar study Mobini et al of outcome following shoulder steroid injection with physiotherapy showed significant outcome only at 6 weeks. ${ }^{19}$ But our study showed even in first group (MUA and physiotherapy) showed better results within a span of 2 weeks with much improvement on later follow-up.

\section{CONCLUSION}

MUA can be considered as better option for primary frozen shoulder as treatment compared to intra articular steroid injection. For immediate pain relief intraarticular steroid injection is better option but immediate improvement in functional outcome is with manipulation under anaesthesia.

\section{Limitations}

No control group was there and sample size is small.

Funding: No funding sources

Conflict of interest: None declared

Ethical approval: The study was approved by the institutional ethics committee

\section{REFERENCES}

1. Naviaser JS. Adhesive capsulitis of the shoulder: A Study of the Pathological Findings in Periarthritis of the Shoulder. JBJS. 1945;27(2):211-22.

2. Ryan V, Brown H, Minns Lowe CJ, Lewis JS. The pathophysiology associated with primary (idiopathic) frozen shoulder: A systematic review. BMC Musculoskelet Disord. 2016;17(1):340.

3. Reeves B. The natural history of the frozen shoulder syndrome. Scand J Rheumatol. 1975;4(4):193-6.

4. Robinson CM, Seah KTM, Chee YH, Hindle P, Murray IR. Frozen shoulder. J Bone Joint Surg Br. 2012;94(1):1-9.

5. Dodenhoff RM, Levy O, Wilson A, Copeland SA. Manipulation under anesthesia for primary frozen shoulder: effect on early recovery and return to activity. J Shoulder Elb Surg. 2000;9(1):23-6.

6. Mobini M, Kashi Z, Bahar A, Yaghubi M. Comparison of corticosteroid injections, physiotherapy, and combination therapy in treatment of frozen shoulder. Pak J Med Sci. 2012;28:648-51.

7. Griesser MJ, Harris JD, Campbell JE, Jones GL. Adhesive capsulitis of the shoulder: a systematic review of the effectiveness of intraarticular corticosteroid injections. J Bone Joint Surg Am. 2011;93:1727-33.

8. Gagey OJ, Gagey N. The hyperabduction test: an assessment of the laxity of the inferior glenohumeral ligament. J Bone Joint Surg Br. 2001;83:69-74.

9. Yoon JP, Chung SW, Kim JE, Kim HS, Lee HJ, Jeong WJ, et al. Intra-articular injection, subacromial injection, and hydrodilatation for 
primary frozen shoulder: a randomized clinical trial. J Shoulder Elbow Surg. 2016;25(3):376-83.

10. Mussa M, Dar IH, Rafeeq SA, Lone AH. Role of Intra-articular Steroid Injection in the Management of Idiopathic Adhesive Capsulitis of the Shoulder. Int J Contemp Med Res. 2016;3(11):3222-3.

11. Breckenridge JD, McAuley JH. Shoulder pain and disability index (SPADI). J Physiotherapy. 2011;57(3):197.

12. Tveitå EK, Ekeberg OM, Juel NG, Bautz-Holter E. Responsiveness of the shoulder pain and disability index in patients with adhesive capsulitis. BMC Musculoskeletal Disorders. 2008;9(1):161.

13. Shin SJ1, Lee SY. Efficacies of corticosteroid injection at different sites of the shoulder for the treatment of adhesive capsulitis. J Shoulder Elbow Surg. 2013;22(4):521-7.

14. Yoon SH, Lee HY, Lee HJ, Kwack KS. Optimal dose of intra-articular corticosteroids for adhesive capsulitis: a randomized, triple-blind, placebocontrolled trial. Am J Sports Med. 2013;41(5):1133-9.

15. Wong PLK, Tan HCA. A review on frozen shoulder: Singapore Med J. 2010;51(9):694-7.

16. Winters JC, Sobel JS, Groenier KH, Arendzen HJH, Meyboom-de Jong B. Comparison of physiotherapy, manipulation, and corticosteroid injection for treating shoulder complaints in general practice: randomized, single blind study. BMJ. 1997;314:1320-6.

17. Chambler AFW, Carr AJ. The role of surgery in frozen shoulder. J Bone Joint Surg Br. 2003;85:789-95.

18. Kivimäki J, Pohjolainen T, Malmivaara A, Kannisto M, Guillaume J, Seitsalo S, et al. Manipulation under anesthesia with home exercises versus home exercises alone in the treatment of frozen shoulder: a randomized, controlled trial with 125 patients. J Shoulder Elbow Surg. 2007;16:722-6.

19. Maryam M, Zahra K, Adeleh B, Morteza Y. Comparison of corticosteroid injections, physiotherapy, and combination therapy in treatment of frozen shoulder. Pak J Med Sci. 2012;28(4):648-51.

Cite this article as: Veeraraghavan RR, Varghese V, Sanjay AK, Vanchi PK, Murugesan MK. Is manipulation under anaesthesia still a better option than intra articular steroid injection in primary frozen shoulder? Int J Res Orthop 2020;6:365-8. 